\title{
STRAIN RATE CHANGE FROM 0.04 TO 0.004\%/S IN AN ENVIRONMENTAL FATIGUE TEST OF CF8M CAST STAINLESS STEEL
}

\author{
ILL-SEOK JEONG*, WANJAE KIM, TAE-RYONG KIM, and HYUN-IK JEON \\ Korea Electric Power Research Institute \\ 103-16, Munjidong, Yuseong, Daejeon, 305-380, Korea \\ *Corresponding author. E-mail : isjeong@ kepri.re.kr
}

Received October 16, 2009

Accepted for Publication October 25, 2010

To define the effect of strain rate variation from $0.04 \%$ to $0.004 \% / \mathrm{s}$ on environmental fatigue of CF8M cast stainless steel, which is used as a primary piping material in nuclear power plants, low-cycle fatigue tests were conducted at operating pressure and temperature condition of a pressurized water reactor, $15 \mathrm{MPa}$ and $315^{\circ} \mathrm{C}$, respectively. A high-pressure and high-temperature autoclave and cylindrical solid fatigue specimens were used for the strain-controlled low-cycle environmental fatigue tests. It was observed that the fatigue life of CF8M stainless steel is shortened as the strain rate decreases. Due to the effect of test temperature, the fatigue data of NUREG-6909 appears a slightly shorter than that obtained by KEPRI at the same stress amplitude of $1 \times 10^{3} \mathrm{MPa}$. The environmental fatigue correction factor $\mathrm{F}_{e n}$ 's calculated with inputs of the test data increases with high strain amplitude, while the $\mathrm{F}_{e n}$ 's of NUREG-6909 remain constant regardless of strain amplitude.

KEYWORDS : Environmental Fatigue, Environmental Fatigue Correction Factor, $\mathrm{F}_{e n}, \mathrm{CF} 8 \mathrm{M}$ Stainless Steel, Pressurized Water Reactor, Strain Rate

\section{INTRODUCTION}

In pressurized water reactors (PWRs), the life of pressure boundary components is significantly affected by environmental fatigue, and some findings confirm that their life can be remarkably decreased as the strain rate of fatigue loading decreases [1-4]. To estimate the effect of strain rate variation of cast stainless steel CF8M on fatigue life in the PWR environment, low-cycle environmental fatigue test were conducted by KEPCO Research Institute (KEPRI) [5].

Fatigue life was measured in terms of the number of cycles with the variation of strain amplitudes at strain rates of $0.04 \% / \mathrm{s}$ and $0.004 \% / \mathrm{s}$. This paper focuses on the effect of various strain rates on the environment fatigue life of CF8M cast stainless steel.

\section{TEST METHODS AND RESULTS}

\subsection{Test Rig and Specimen}

The locally fabricated test rig is shown in Figs. 1-2. The test rig consists of an autoclave chamber, a hightemperature and pressurized water loop, a data acquisition system (DAQ), and control equipment. The rig simulates
PWR operating conditions by controlling dissolved oxygen, $\mathrm{pH}$, and conductivity. The loop operating temperature is $315^{\circ} \mathrm{C}$, and the operation pressure is $15 \mathrm{MPa}$. Design parameters of the test rig and loop are summarized as follows:

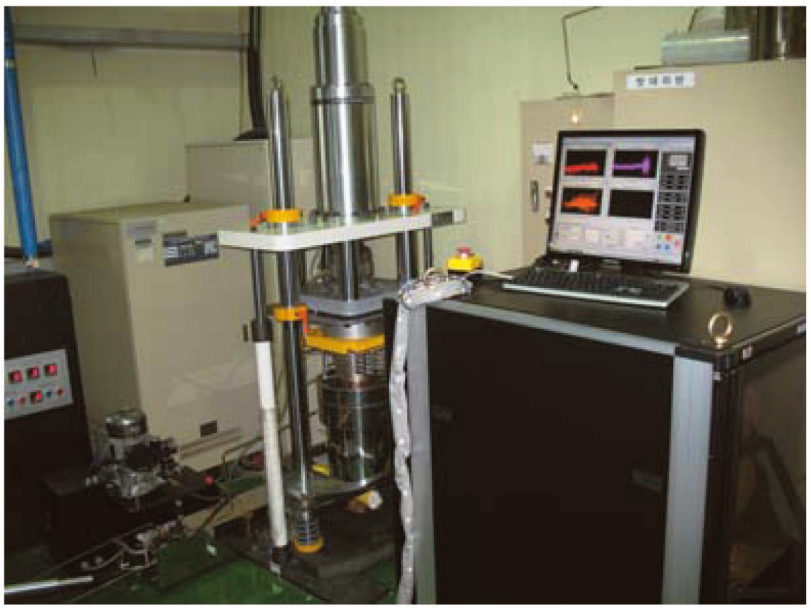

Fig. 1. Low-Cycle Fatigue Test Rig 
- Maximum temperature: $350^{\circ} \mathrm{C}$

- Maximum pressure: $17 \mathrm{MPa}$

- Dissolved oxygen: $<5 \mathrm{ppb}$

- Conductivity: <30 $\mu \mathrm{S} / \mathrm{cm}$

- Autoclave: 6 liters, electrical heating

- Load Frame assembly: $50 \mathrm{kN}$

- Servo electric actuator: $50 \mathrm{kN}, 30 \mathrm{~mm}$ stroke

Fig. 3 depicts the features of the cylindrical solid fatigue specimen used in the test. Test specimen blocks were manufactured conservatively with a ferrite content of $25 \mathrm{wt} . \%$ based on a review of a certified material test report (CMTR) for a domestic power plant. Test specimens were fabricated according to ASTM E 606-92 [6]. Table 1 shows the chemical composition of the material. Fig. 4 shows the microstructure of the test material CF8M stainless steel which has duplex phase of $\delta$-ferrites in an austenitic matrix [7].

\subsection{Test Conditions and Procedures}

Low-cycle environmental fatigue test conditions, such as strain rate, strain amplitude, load ratio (R), temperature, pressure, and dissolved oxygen are shown in Table 2. Fatigue loading by a strain-controlled method was imposed. The monitored strain at the shoulders of

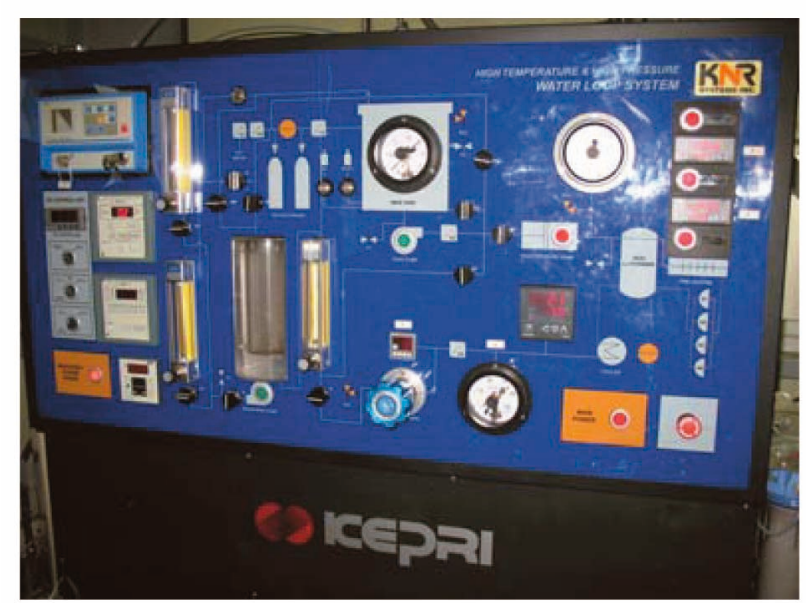

Fig. 2. Test Loop

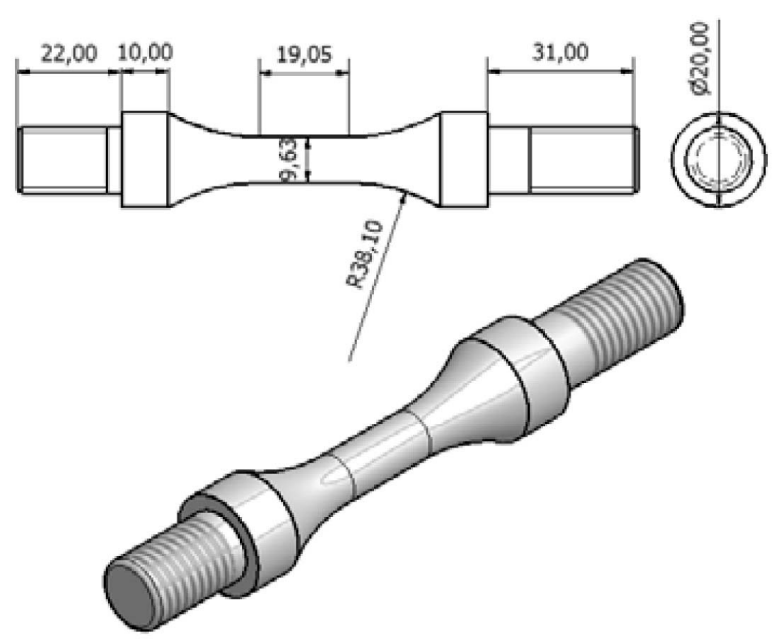

Fig. 3. Cylindrical Solid Fatigue Test Specimen
Table 1. Chemical Composition of CF8M

\begin{tabular}{c|c|c|c|c|c|c|c}
\hline $\mathrm{C}$ & $\mathrm{Mn}$ & $\mathrm{Si}$ & $\mathrm{Cr}$ & $\mathrm{Ni}$ & $\mathrm{Mo}$ & $\mathrm{S}$ & $\mathrm{P}$ \\
\hline 0.04 & 0.79 & 1.35 & 19.0 & 9.3 & 2.4 & 0.013 & 0.02 \\
\hline
\end{tabular}

Table 2. Test Conditions

\begin{tabular}{c|c}
\hline Load Ratio $(\mathrm{R})$ & -1 \\
\hline Strain Rate & $0.04,0.004 \% / \mathrm{s}$ \\
\hline Strain Amplitude $\left(\varepsilon_{\mathrm{a}}\right)$ & $0.3,0.4,0.6,0.8 \%$ \\
\hline Temperature & $315^{\circ} \mathrm{C}$ \\
\hline Pressure & $15 \mathrm{MPa}$ \\
\hline Dissolved Oxygen $(\mathrm{DO})$ & $<5 \mathrm{ppb}$ \\
\hline
\end{tabular}

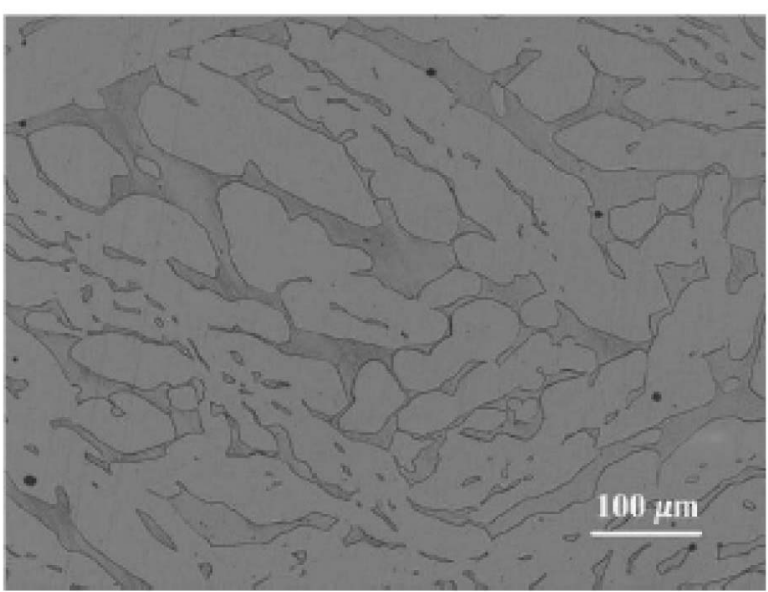

Fig. 4. Optical Microstructure of Test Material 
the specimen with LVDT inside the autoclave was converted to the strain of the specimen gauge length with a correlation of displacements analyzed by an FEM method. This procedure was used in a previous study [8]. Fatigue life was determined on the basis of the number of cycles at which the fatigue tension load was first reduced by $25 \%$ [9].

\subsection{Cyclic Strain Hardening Effect}

CF8M stainless steel has the feature of cyclic strain hardening $(\mathrm{CSH})$ in low-cycle fatigue test with straincontrol. That is, the maximum stress increases during initial cycle repetitions. Fig. 5 shows the maximum fatigue

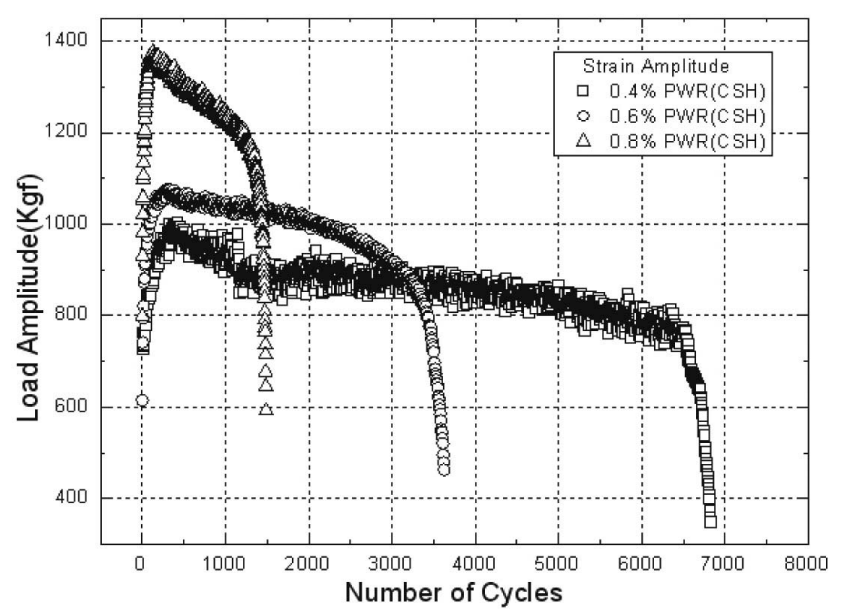

Fig. 5. Relation of Maximum Load and Fatigue Life [10]

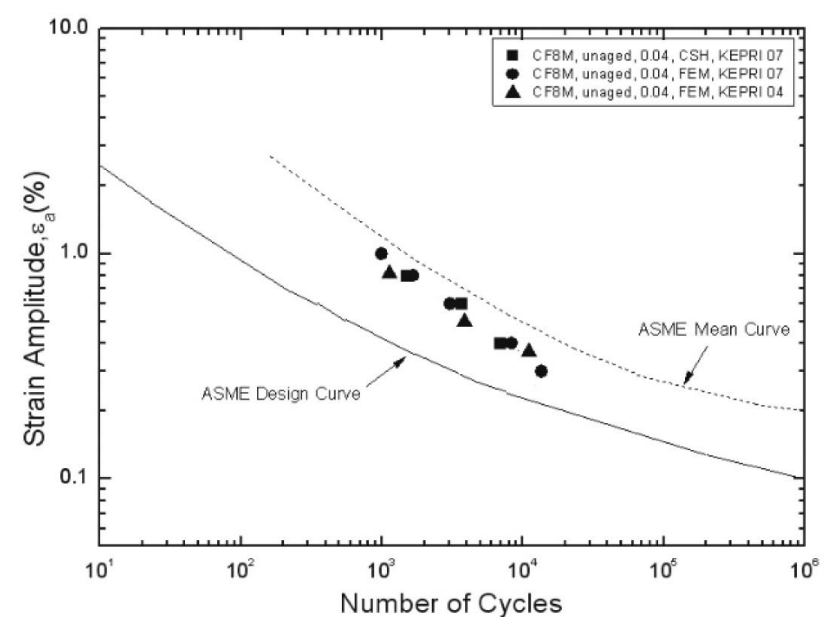

Fig. 6. Comparison of the Cyclic Strain-Hardening Effect Between CSH and FEM [10] tension load versus the number of fatigue cycles at the strain rate of $0.04 \% / \mathrm{s}$. As shown in Fig. 5, the CSH effect appears as the load increases in the early stages below 200 cycles. It becomes stable and then reaches fatigue life cycles.

A test procedure which was developed to incorporate the $\mathrm{CSH}$ into the environmental fatigue test was presented in previous studies $[10,11]$. A displacement relation formula between the gauge length (R.G., real gauge) and the shoulder length (S.G., shoulder gauge) of the specimen was derived from simultaneously measured displacement data of a preliminary fatigue test in a hot air environment of $315^{\circ} \mathrm{C}$ with strain control at the gauge length. The data at the gauge length was taken by an extensometer, and that of the shoulder length was taken by the LVDT. During the environmental fatigue test under PWR conditions, the shoulder length displacement of the specimen in the high-temperature and high-pressure autoclave was converted to that of gauge length by the displacement relation formula in order to simulate the $\mathrm{CSH}$.

The numbers of fatigue cycles tested by this procedure at the strain rate $0.04 \% / \mathrm{s}$ are plotted as square dots in Fig. 6. These results show good agreement with the circle and triangle data produced by the FEM calibration procedure [8]. To confirm these results, environmental fatigue tests at the strain rate of $0.004 \% / \mathrm{s}$ in a PWR environment were performed using the FEM calibration procedure to save test time.

\subsection{Result and Discussions}

The result of the low-cycle environmental fatigue tests are shown in Tables 3 and 4 . The result of this test shows the decrease in fatigue life as the strain amplitude increases at a same strain rate. Fig. 7 shows the

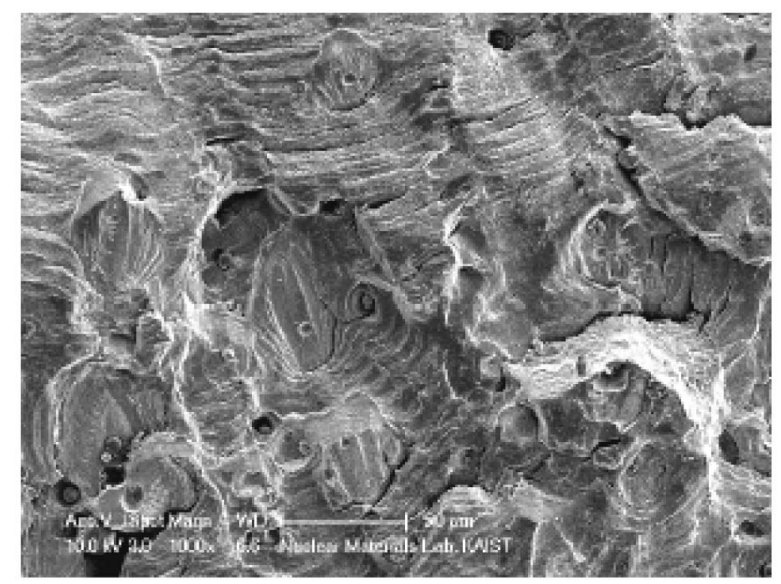

Fig. 7. SEM Microstructure of Fatigue Crack Surface of the Tested Specimen at Strain Amplitude $0.6 \%$ and Strain Rate $0.04 \% / \mathrm{s}$ [7] 
Table 3. Result of Low-Cycle Fatigue Test in PWR Water at Strain Rate $0.04 \% / \mathrm{s}$

\begin{tabular}{c|c|c|c|c}
\hline \multirow{2}{*}{} & \multicolumn{4}{|c}{ Strain amplitude (\%) } \\
\cline { 2 - 5 } & 0.3 & 0.4 & 0.6 & 0.8 \\
\hline $\begin{array}{c}\text { Strain rate } \\
(\% / \mathrm{s})\end{array}$ & 0.04 & 0.04 & 0.04 & 0.04 \\
\hline $\begin{array}{c}\text { Frequency } \\
(\mathrm{Hz})\end{array}$ & 0.0333 & 0.025 & 0.0167 & 0.0125 \\
\hline $\begin{array}{c}\text { Fatigue life } \\
\text { (cycles) }\end{array}$ & 13,505 & $\begin{array}{c}6,818 \\
8,300\end{array}$ & $\begin{array}{c}3,610 \\
3,040\end{array}$ & $\begin{array}{c}1,473 \\
1,660\end{array}$ \\
\hline
\end{tabular}

Table 4. Result of Low-Cycle Fatigue Test in PWR Water at Strain Rate $0.004 \% / \mathrm{s}$

\begin{tabular}{c|c|c|c}
\hline \multirow{2}{*}{} & \multicolumn{3}{|c}{ Strain amplitude (\%) } \\
\cline { 2 - 4 } & 0.4 & 0.6 & 0.8 \\
\hline Strain rate $(\% / \mathrm{s})$ & 0.004 & 0.004 & 0.004 \\
\hline Frequency $(\mathrm{Hz})$ & 0.0025 & 0.00167 & 0.00125 \\
\hline Fatigue life (cycles) & $\begin{array}{l}2786 \\
2434\end{array}$ & 555 & 153 \\
\hline
\end{tabular}

microstructure of a fatigue crack surface of the tested specimen at the strain amplitude of $0.6 \%$ and the strain rate of $0.04 \% / \mathrm{s}$ [7].

The environmental fatigue test results shown in Tables 3 and 4 were compared to evaluate the effect of strain rate on fatigue life. Fig. 8 shows reduced fatigue life with decreased strain rate for the same strain amplitude. Decreasing the strain rate from 0.04 to $0.004 \% / \mathrm{s}$ resulted in a more reduced fatigue life estimatation at higher strain amplitudes.

Fatigue life data are plotted for the strain rates of $0.04 \% / \mathrm{s}$ and $0.004 \% / \mathrm{s}$ in Fig. 9. Fatigue life decreases as the strain rate is reduced. The difference in fatigue life between the two strain rates increases as the strain amplitude increases for long tension periods at high strain amplitudes which actively caused corrosion on the specimen surface inside the autoclave environment.

A comparison of the S-N (stress-life cycle) curve of this test data and and that of NUREG-6909 [9] is shown in Fig. 10. At the same stress amplitude of $1 \times 10^{3} \mathrm{MPa}$, the data of NUREG-6909 shows a slightly shorter fatigue life than that obtained by KEPRI. This result seems to be for the effect of higher test temperature of NUREG-6909 of $325^{\circ} \mathrm{C}$ rather than the KEPRI test temperature of $315^{\circ} \mathrm{C}[12]$.

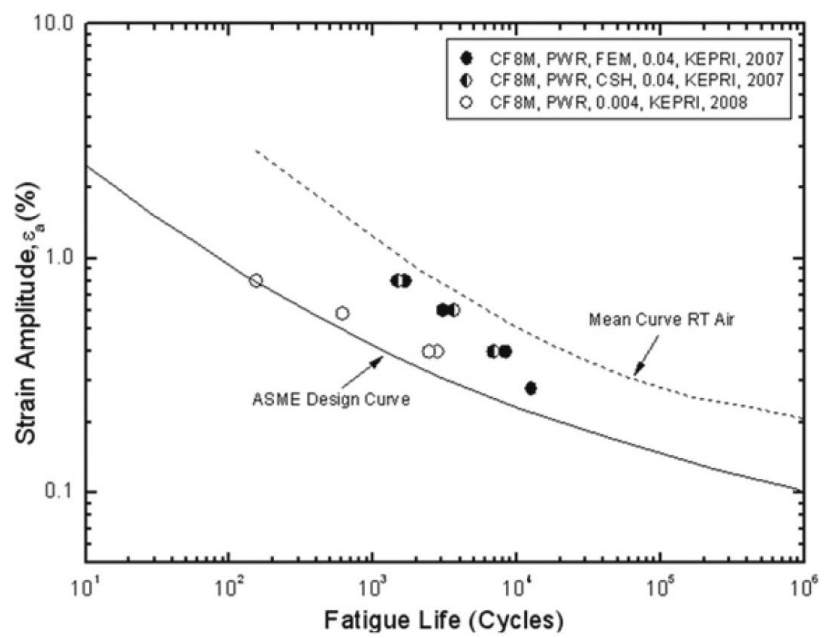

Fig. 8. Relationship of Strain Amplitude to Fatigue Life for CF8M in PWR Water

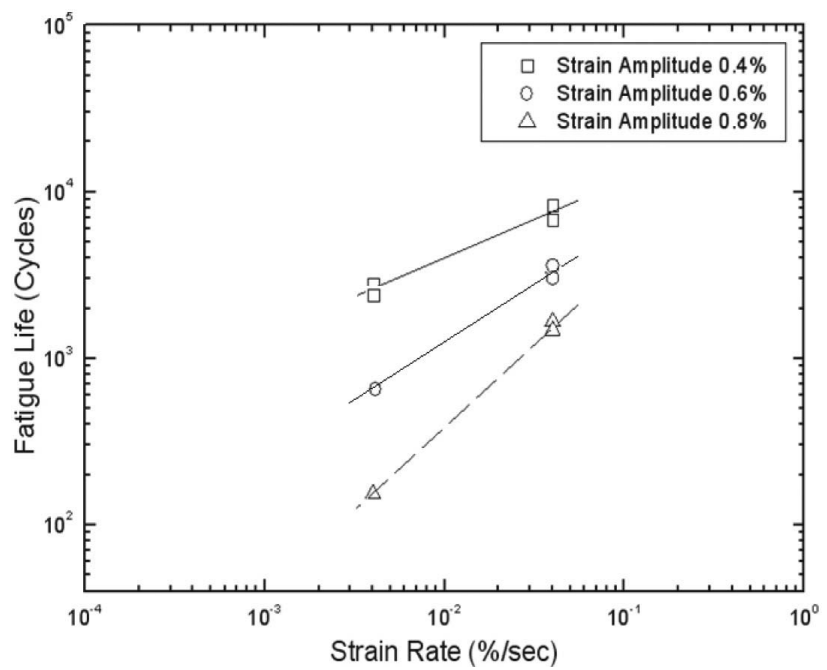

Fig. 9. Relationship of Fatigue Life to Strain Rate for CF8M in PWR Water

In Fig. 11, environmental fatigue life correction factors, $\mathrm{F}_{e n}$, are calculated with the formula of NUREG6909 and the estimated ratio of the number of cycles in the fatigue test at room temperature in air to the number of cycles in the environmental fatigue test. The data represented by circles are $\mathrm{F}_{e n}$ 's derived from KEPRI environmental fatigue data and KEPRI room-temperature (RT) air data. The data represented by rectangles was derived from the KEPRI environmental fatigue test and the ASME RT air fatigue mean curve.

The calculated $\mathrm{F}_{e n}$ of NUREG-6909 is a constant with strain amplitude because strain amplitude is not an 


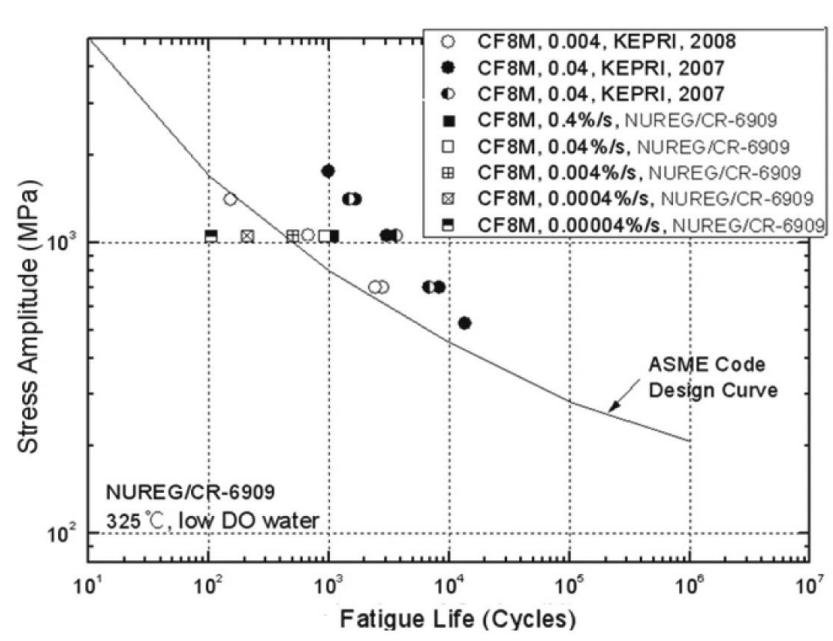

Fig. 10. Comparison with S-N of NUREG-6909

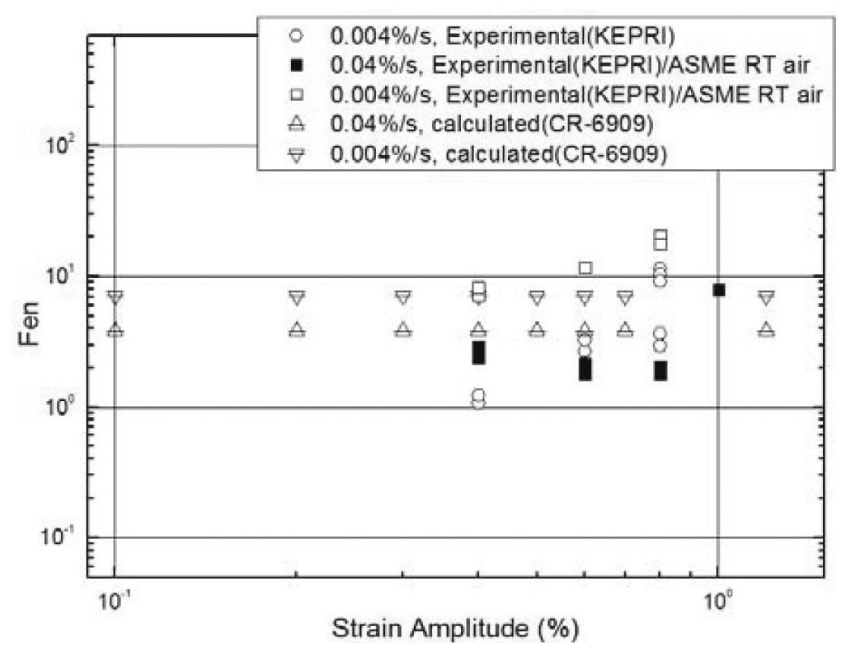

Fig. 11. Comparison with $\mathrm{F}_{e n}$ of NUREG-6909

independent variable in the $\mathrm{F}_{e n}$ formula of NUREG-6909. However, $\mathrm{F}_{e n}$ 's estimated from the KEPRI test data vary with strain amplitudes. That is, $\mathrm{F}_{e n}$ increases with increasing strain amplitude except the solid circles of the KEPRI test data at the strain rate of $0.04 \% / \mathrm{s}$. This indicates that the $\mathrm{F}_{e n}$ formula of NUREG- 6909 needs to be modified by including an influencing parameter of strain amplitude.

The lower strain rate condition has more influence on environmental fatigue life with high $\mathrm{F}_{e n}$. The $\mathrm{F}_{e n}$ 's derived from the specific KEPRI CF8M test data obtained at the strain rate of $0.004 \% / \mathrm{s}$ are generally lower than those of NUREG-6909 for the conservatism of the $\mathrm{F}_{e n}$ approach.

\section{CONCLUSIONS}

This research provides test data of low-cycle fatigue life of CF8M stainless steel under a PWR environment and investigates the effect on fatigue life of strain rate variation from $0.04 \% / \mathrm{s}$ to $0.004 \% / \mathrm{s}$ by comparison with other research results.

As is well known, it is confirmed that the fatigue life of CF8M stainless steel decreases as the strain rate decreases. At the same stress amplitude of $1 \times 10^{3} \mathrm{MPa}$, the fatigue data of NUREG-6909 shows a slightly shorter life than the data obtained by KEPRI due to the effect of test temperature. The $\mathrm{F}_{e n}$ formula of NUREG-6909, in which strain amplitude is not included as an influencing parameter, needs to be modified based on the results of this investigation.

\section{ACKNOWLEDGMENT}

This research was conducted as a part of the Nuclear Plant Technology Innovation Program of the Ministry of Education, Science, and Technology and was supported by the Korea Institute of Energy Technology Evaluation and Planning.

\section{REFERENCES}

[ 1 ] D.A. Gerber: Evaluation of Environmental Fatigue Effects for a Westinghouse Nuclear Power Plant, EPRI TR-110043, 1998

[2] M. Higuchi: Effect of Strain Holding and Continuously Changing Strain Rate on Fatigue Life Reduction of Structural Materials in Simulated LWR water, PVP2007-26101, 2007

[ 3 ] Y.S. Garud, et.al.: Corrosion Fatigue of Water-Touched Pressure Retaining Components in Power Plants, EPRI TR-106696, 1997

[4 ] O.K. Chopra: Effects of LWR Coolant Environments on Fatigue Design Curves of Fatigues of Austenitic Stainless Steels, NUREG/CR-5704, 1999

[ 5 ] I.S. Jeong, G.H. Ha, T.R. Kim, H.I. Jeon and Y.S. Kim: Effect of Strain Rate 0.04 to $0.004 \%$ /s on Environmental Fatigue of CF8M Stainless Steel, Transactions of the Korean Nuclear Society, Spring Meeting, Jeju, Korea, May 2009

[6] Standard Practice for Strain-Controlled Fatigue Testing, ASTM E 606-92, pp. 523-537, 1993

[ 7 ] P.Y. Cho, H. Jang, I.S. Jeong and C.H. Jang: Environmental Behavior of Wrought and Cast Stainless Steels in $310^{\circ} \mathrm{C}$ Deoxygenated Water, ICAP '09, Paper 9407, Tokyo, Japan, 2009

[ 8 ] I.S. Jeong, G.H. Ha and T.R. Kim: Environmental Fatigue Test of CF8M with a Small Autoclave Simulating PWR Conditions, ASME PVP2008-61673, Chicago, Illinois, US, 2008,

[9] O.K. Chopra and W. J. Shack: Effect of LWR Coolant Environments on the Fatigue Life of Reactor Materials, Final Report, NUREG/CR-6909, ANL-06/08, US Nuclear Regulatory Commission, 2007

[10] I.S. Jeong, G.H. Ha, T.R. Kim and H.I. Jeon: Characteristics of the Cyclic Hardening in Low Cycle Environmental Fatigue Test of CF8M Stainless Steel, Journal of Korea 
Society of Mechanical Engineers A, Vol.32 No.2, 177-185 (Korean), 2008

[11] I.S. Jeong, G.H. Ha and H.I. Jeon: Strain Hardening Effect of CF8M Stainless Steel in the Environment Fatigue Test under Pressurized Water Reactor Condition, Journal of
Loss Prevention in the Process Industries, 22 (2009), 879-883

[12] O.K. Chopra and W.J. Shack: Review of the Margins for ASME Code Fatigue Design Curve-Effects of Surface Roughness and Material Variability, NUREG/CR-ANL02/39, US Nuclear Regulatory Commission, 2003 